\title{
Ongewenste effecten van voorlichting over recreatief drugsgebruik
}

\section{Een toetsingskader bij de ontwikkeling van harm reduction-interventies}

\section{Desirée B. Spronk · Lotte Voorham · Ferry X. Goossens}

Published online: 23 January 2020

(c) The Author(s) 2020

\begin{abstract}
Samenvatting In Nederland is drugspreventie een belangrijk onderdeel van het drugsbeleid. Harm reduction-interventies die zich richten op voorlichting over recreatief drugsgebruik vormen daarbinnen een belangrijke categorie. De nadruk ligt hierbij op het voorkómen van gezondheidsschade bij gebruik en niet zozeer op het voorkómen van het drugsgebruik op zich. Tegen de achtergrond van een stijging in het gebruik van verschillende soorten drugs is het van belang om kritisch te blijven en na te gaan of er bij voorlichting over recreatief drugsgebruik ook ongewenste effecten optreden. We presenteren hieronder een praktisch toetsingskader dat ondersteuning biedt bij het inschatten van eventuele ongewenste effecten bij dit type harm reduction-interventies.
\end{abstract}

Trefwoorden harm reduction - ongewenste effecten . interventieontwikkeling · drugsvoorlichting · drugspreventie

\section{Harm reduction}

'Harm reduction' wordt gedefinieerd als 'het beleid, de programma's en de praktijk die als doelstelling hebben de negatieve gezondheids-, sociale en economische effecten van het gebruik van legale en illegale middelen te verminderen, zonder het gebruik zelf te beperken' [1]. Een klassieke harm reduction-interventie is bijvoorbeeld het aanbieden van schone naalden voor verslaafde gebruikers van heroïne. Een andere vorm is het gebruik van voorlichtingsmaterialen die zich richten op de recreatieve, niet-verslaafde gebruiker. Voorbeelden zijn websites, flyers en video's met informatie over drugs of peer-to-peer-organisaties (bijvoorbeeld

Dr. D. B. Spronk $(\bowtie) \cdot$ L. Voorham · Dr. F. X. Goossens Trimbos-instituut, Utrecht, Nederland

dspronk@trimbos.nl
TeamAlert, Unity, LOS) die voorlichting geven op festivals. De voorlichting kan gaan over drugs die populair zijn in het uitgaansleven of het gebruik van drugs tijdens de seks en de risico's hiervan. In Nederland zijn er verschillende instanties die aan drugsvoorlichting doen, zoals de instellingen voor verslavingszorg, Mainline en het Trimbos-instituut. Hoewel het format van de voorlichting van organisatie tot organisatie verschilt, hebben deze instanties met elkaar gemeen dat ze interventies ontwikkelen die uitleg geven over de manier waarop de persoonlijke gezondheidsschade bij het gebruik van drugs zo veel mogelijk beperkt kan worden.

\section{Kloof tussen theorie en praktijk}

Bij het ontwikkelen van interventies zijn er verschillende belanghebbenden betrokken, zoals (het team van) interventieontwikkelaars, organisaties of partijen die de interventie financieren, mensen die de interventie zullen gaan uitvoeren en de groep mensen voor wie de interventie bedoeld is (de doelgroep). Deze partijen dragen bij aan het tot een succes maken van een interventie. Hoewel het toetsingskader zich voornamelijk richt op de inhoudelijke ontwikkeling van interventies, is het belangrijk om te beseffen dat verschillende partijen hier een rol bij spelen en dat deze partijen ook gevraagd kan worden om mee te denken over nadelige effecten.

Voor de inhoudelijke ontwikkeling van interventies wordt er idealiter gebruikgemaakt van een onderbouwde en gestructureerde methode, zoals intervention mapping [2]. Theoretische inzichten worden gebruikt om vragen te beantwoorden als 'welk gedrag moet er veranderd worden?' en 'welke stappen moeten er gezet worden om dat doel te bereiken?'. Een dergelijke methode helpt om in theorie een effectieve interventie te ontwikkelen die uitvoerbaar is in de 
praktijk. Het uitvoeren van een evaluatieonderzoek naar de (ongewenste) effecten van de interventie is daarbij een belangrijke stap.

Soms is deze stap in de dagelijkse praktijk van de ontwikkeling van voorlichting over drugsgebruik niet altijd mogelijk. Daar liggen vaak heel basale oorzaken aan ten grondslag, zoals een tekort aan mankracht of geld. Maar ook het moeilijk kunnen bereiken van deelnemers, het niet kunnen vaststellen van een causale relatie of beperkte mogelijkheden voor randomisatie van deelnemers over een interventie- en een controlegroep kunnen oorzaken zijn. Dit betekent dat voorlichtingsmaterialen over drugs lang niet altijd op effectiviteit zijn geëvalueerd. Ze kunnen wel ingezet worden, maar het is dan van belang om goed na te gaan of de interventie niet onbedoeld schade aanricht.

Uit de literatuur en het maatschappelijk debat weten we namelijk dat ook in theorie effectieve interventies met ongewenste effecten kunnen samengaan [3]. Een kritische afweging van mogelijke ongewenste effecten is daarom sterk aan te raden. Om interventieontwikkelaars hierbij te ondersteunen heeft het Trimbos-instituut een praktisch toetsingskader ontwikkeld. Op basis hiervan kan laagdrempelig worden nagedacht over mogelijk ongewenste effecten. Met het toetsingskader kunnen ongewenste effecten van voorlichting over recreatief drugsgebruik in kaart worden gebracht.

\section{Nadelige effecten}

\section{Suboptimale gezondheidsboodschap}

De voorlichting stimuleert wel gezonder gedrag, maar informeert niet over het 'gezondst' mogelijke gedrag, waardoor de aanpak van het gezondheidsprobleem niet optimaal is. Er zijn verschillende valkuilen.

De eerste valkuil is het niet benoemen van onthouding (niet gebruiken). Acceptatie van gebruik is een van de kernpunten van harm reduction. Hierdoor wordt echter soms ten onrechte verondersteld dat onthouding niet binnen harm reduction past, terwijl het zeker ook tot de mogelijke doelen behoort [4]. Sterker nog, vanuit het oogpunt van de gezondheidsbevordering is abstinentie het meest efficiënt in het beperken van de nadelige gevolgen van drugsgebruik. Anders dan bij de groep verslaafde gebruikers is het voor recreatieve gebruikers in principe mogelijk om relatief eenvoudig met het gebruik te stoppen. Wanneer deze optie niet wordt benoemd, ziet een deel van de gebruikers de gezondste optie mogelijk over het hoofd. Het is daarom goed om na te gaan of niet gebruiken ook een plek in de interventie verdient.

Een tweede valkuil is een harm reduction-boodschap die niet geschikt is voor mensen buiten de doelgroep. Bij voorlichtingsmaterialen is de doelgroep de recreatieve en zelfreflecterende gebruiker. Veel voorlichtingsmaterialen bereiken echter één grote en ongedifferentieerde groep gebruikers. Hierdoor zou een (beginnende) probleemgebruiker niet de juiste boodschap kunnen ontvangen. Voor deze groep is het goed om meer maatwerk te leveren en bijvoorbeeld te verwijzen naar hulpverlening, zoals een huisarts. Bij schriftelijke voorlichtingsmaterialen zou er een verwijzing naar een hulpdienst vermeld kunnen worden.

De laatste valkuil is het niet benoemen van het beste, minst schadelijke, alternatief. Een voorbeeld is wanneer cannabisgebruikers wordt aangeraden om cannabis zonder tabak te roken. Een 'minder schadelijk' alternatief is informeren over het gebruik van een vaporiser. Of er daadwerkelijk een 'minder schadelijk' alternatief is hangt af van de aard en het doel van de interventie. De interventieontwikkelaar dient zichzelf af te vragen of er andere gedragsalternatieven zijn waarop beter kan worden ingezet.

\section{Stimuleren van drugsgebruik (tegenovergestelde effect)}

Een gevaar is dat de interventie het tegenovergestelde effect heeft of onbedoelde gevolgen op maatschappelijk niveau veroorzaakt. Het kan voorkomen dat de interventie aanzet tot gebruik of tot meer risicovol gebruik.

Er zijn gevallen waarbij blootstelling aan gezondheidswaarschuwingen hebben geleid tot een toename in middelengebruik [5]. Een voorbeeld zijn gezondheidsboodschappen met een angstopwekkende boodschap [6]. Het is dus belangrijk om na te denken over de formulering van de gezondheidsboodschap.

Verschillende mechanismen kunnen bijdragen aan een toename in gebruik. Een voorbeeld is de maatschappelijke beïnvloeding van sociale normen. Dit betekent dat de inschatting met betrekking tot het vóórkomen van drugsgebruik de acceptatie van drugsgebruik in de maatschappij bevordert. Uit alcoholonderzoek blijken deze normen bij te dragen aan gebruik [7]. Of verandering van sociale normen ook daadwerkelijk tot een toename van drugsgebruik zal leiden blijft overigens de vraag en is lastig aan te tonen.

Dit geldt ook voor veranderingen in risicoperceptie. Hierbij gaat het over de persoonlijke inschattingen die mensen maken over de nadelige gevolgen van drugsgebruik en de kans dat die bij hen optreden. Een hoge risicoperceptie is in het algemeen een beschermende factor voor drugsgebruik [8]. Drugspreventie richt zich vaak op het verhogen van deze risicoperceptie door het noemen van de risico's van gebruik en hoe je deze kunt verkleinen. Het kan zo zijn dat de risicoperceptie verlaagd wordt nadat een gebruiker actie heeft ondernomen om het gezondheidsrisico te verkleinen (risk appraisal-hypothese) [9]. Wanneer in de voorlichting bijvoorbeeld geadviseerd wordt om naar een chill-out-ruimte te gaan wanneer je MDMA hebt gebruikt, en dit advies ook daadwerkelijk opgevolgd wordt, dan kan de persoonlijke risicoperceptie van deze gebruiker over de tijd systematisch dalen. Een lage risicoperceptie is in verband gebracht met 
Tabel 1 Toetsingskader harm reduction-interventies bij recreatief drugsgebruik

\begin{tabular}{|c|c|c|c|}
\hline \multicolumn{4}{|l|}{ 1. Welk gezondheidsprobleem probeert de interventie op te lossen? } \\
\hline \multicolumn{4}{|l|}{ 2. Wat is het risicogedrag dat de interventie beoogt te veranderen? } \\
\hline \multicolumn{4}{|c|}{$\begin{array}{l}\text { 3. Op welke manier beoogt de interventie het risicogedrag te verminderen? Welke aspecten van gedrag wil je veranderen, en welk mechanisme gebruik je } \\
\text { hiervoor? }\end{array}$} \\
\hline & Goed geregeld & Nog even naar kijken & $\begin{array}{l}\text { Nog veel aan verande- } \\
\text { ren }\end{array}$ \\
\hline \multicolumn{4}{|l|}{ 4. Is er in de interventie aandacht voor stoppen met drugsgebruik? } \\
\hline \multicolumn{4}{|l|}{$\begin{array}{l}\text { Beschrijf in hoeverre de doelgroep alternatieven heeft voor het risicovolle gedrag. } \\
\text { Beschrijf in hoeverre de interventie hier aandacht aan geeft en wijst op andere } \\
\text { interventies die hier op aansluiten }\end{array}$} \\
\hline \multicolumn{4}{|l|}{$\begin{array}{l}\text { Kan de interventie worden aangepast zodat er rekening wordt gehouden met de } \\
\text { mogelijkheid van niet-gebruik? }\end{array}$} \\
\hline \multicolumn{4}{|l|}{$\begin{array}{l}\text { 5. Is er een kans dat de interventie een ongewenst effect heeft op het drugsge- } \\
\text { bruik van de doelgroep? }\end{array}$} \\
\hline \multicolumn{4}{|l|}{$\begin{array}{l}\text { Beschriff wat de eventuele ongewenste effecten van de interventie kunnen zijn. } \\
\text { Op welke manier zou dit de doelgroep negatief kunnen beïnvloeden? }\end{array}$} \\
\hline \multicolumn{4}{|l|}{$\begin{array}{l}\text { Kan de interventie worden aangepast zodat de kans op ongewenste bijwerkingen } \\
\text { kleiner wordt? En zo ja, hoe? }\end{array}$} \\
\hline \multicolumn{4}{|l|}{$\begin{array}{l}\text { 6. Is er een kans dat de interventie een ongewenst effect heeft op het drugsge- } \\
\text { bruik van de niet-doelgroep? }\end{array}$} \\
\hline \multicolumn{4}{|l|}{$\begin{array}{l}\text { Beschrijf wat de eventuele ongewenste effecten van de interventie voor de niet- } \\
\text { doelgroep kunnen zijn. Op welke manier zou dit de niet-doelgroep negatief kun- } \\
\text { nen beïnvloeden? }\end{array}$} \\
\hline $\begin{array}{l}\text { Kan de interventie worden aangepast zodat de kans op ongewenste bijwerkingen } \\
\text { kleiner wordt? En zo ja, hoe? }\end{array}$ & & & \\
\hline
\end{tabular}

een stijging in het drugsgebruik en is daarom een belangrijke factor van bewustwording bij de ontwikkeling van voorlichtingsmateriaal [10].

Een belangrijke groep waarmee rekening moet worden gehouden zijn de mensen voor wie de interventie niet bedoeld is (niet-doelgroep). Voorlichting kan de niet-doelgroep nieuwsgierig maken en op een idee brengen. Extra kwetsbare groepen zijn bijvoorbeeld niet-gebruikende festivalgangers die blootgesteld worden aan posters over drugsgebruik, terwijl de beschikbaarheid van drugs op dat moment erg groot is. Ook pubers die wat vaker experimenteren zullen informatie over drugs met extra interesse volgen. Voorlichtingsmaterialen moeten daarom zo veel mogelijk uit de buurt van de niet-doelgroep en in het bijzonder kwetsbare groepen gehouden worden. Er moet goed worden nagedacht over hoe en waar de implementatie plaatsvindt.

Daarnaast kan blootstelling aan drugsgerelateerde plaatjes mogelijk leiden tot een zogenaamde 'cue reactiviteit'. Dat is een automatische, aangeleerde reactie, waarbij het zien van plaatjes die gerelateerd zijn aan het gebruik handelingen activeren die bij drugsgebruik horen [11]. Dit is vooral voor de groep probleemgebruikers lastig. Ook hier is het belangrijk om je af te vragen in hoeverre de voorlichting geschikt is voor een recreatieve gebruiker die op het randje zit van problematisch gebruik. Als zeer beeldend materiaal onder deze groep verspreid wordt, is het beter om de plaatjes die met gebruik samenhangen weg te laten.

\section{Het toetsingskader}

Het toetsingskader (tab. 1) is ontwikkeld door onderzoekers van het Trimbos-instituut. Het is tot stand gekomen in samenwerking met experts op het gebied van interventieontwikkeling, die inhoudelijke aanbevelingen hebben gegeven. Deze experts hebben een pretest uitgevoerd met een eerste versie van het instrument (zie ook de beschouwing), waarna er een evaluatie van het instrument heeft plaatsgevonden. Op basis van de feedback die uit deze evaluatie naar voren is gekomen zijn er nog enkele aanpassingen gedaan. Zo werd de bruikbaarheid verhoogd, wat tot het huidige instrument heeft geleid.

Het instrument start met drie open hulpvragen, gevolgd door drie evaluatievragen. De hulpvragen zijn afgeleid uit de intervention mapping-methode en maken het doel van de interventie duidelijk. Bij vraag 1 gaat het erom inzicht te krijgen in het gezondheidsprobleem. Bij voorlichting over ecstasygebruik kan het bijvoorbeeld gaan om het voorkómen van oververhitting. In een voorlichtingsvideo over alcohol en verkeer gaat het over het voorkómen van verkeersongelukken. Bij vraag 2 gaat het om het definiëren van het risicogedrag waar je je interventie op wilt richten. Hier kan het gaan om te weinig water drinken bij ecstasygebruik, of het onder invloed in de auto stappen. Bij vraag 3 gaat het erom op welke manier je denkt het risicogedrag te veranderen. Hierbij kan het helpen om je te verdiepen in wat de gedragsveranderingstechnieken zijn (behaviour change techniques, BCT's) [12]. BCT's zijn de kleinste componenten van gedragsverandering die op zichzelf de potentie hebben om ge- 
drag te veranderen. Voorbeelden zijn het laten kiezen voor alternatieve vormen van (openbaar) vervoer na drugsgebruik of het informeren over de mogelijkheden om oververhitting te voorkomen.

Vraag 4 tot en met 6 stimuleren om over mogelijke ongewenste effecten na te denken. In het tekstveld kan aangegeven worden wat ongewenste effecten kunnen zijn, wat het onderliggende mechanisme is en hoe ze gereduceerd kunnen worden. Met behulp van drie antwoordopties kan worden aangegeven in hoeverre de interventie 1) goed opgezet is, 2) een kleine aanpassing vergt, of 3) een grote aanpassing vereist. Het instrument kan individueel ingevuld worden en/of gevolgd worden door een discussie in teamverband, waarin ook de uitvoerders betrokken worden. Op basis van de actielijst kan het interventieontwerp of het implementatieplan worden aangepast.

\section{Beschouwing}

We hopen dat dit artikel en het toetsingskader bijdragen aan de ontwikkeling van evenwichtige interventies waarin aandacht is voor eventuele ongewenste effecten. De besproken nadelige effecten en de mechanismen zijn zeker niet compleet, maar vormen een eerste aanzet om de discussie over mogelijke nadelige effecten van drugsvoorlichting op gang te brengen. Harm reduction levert een belangrijke bijdrage aan het voorkomen van drugsgerelateerde gezondheidsincidenten. Het blijkt echter ook noodzakelijk om kritisch na te denken over de ontwikkeling en inzet van de interventie.

Het toetsingskader is tijdens twee groepsbijeenkomsten gebruikt, waarbij verschillende experts op het gebied van interventieontwikkeling aanwezig waren. Tijdens deze bijeenkomsten werd een voorlichtingsfolder over het gebruik van drugs geëvalueerd. Het invullen van het instrument heeft geleid tot een advies om de implementatiekanalen van deze folder te herzien. Na deze bijeenkomsten zijn gesprekken met de experts gevoerd om te achterhalen wat ze van het gebruik van het toetsingskader vonden. Het toetsingskader werd in het algemeen als nuttig ervaren. Wel zijn er naar aanleiding van deze gesprekken aanpassingen gemaakt aan het instrument om de bruikbaarheid te vergroten.

Het toetsingskader is ontwikkeld en gebruikt voor het toepassingsgebied van drugs en voorlichting. Het is niet ondenkbaar dat het ook bij de ontwikkeling van andere (harm reduction-)interventies bruikbaar is. We nodigen interventieontwikkelaars graag uit om hun ervaringen met het toetsingskader met ons te delen. Het toetsingskader is gratis te downloaden vanaf www.trimbos.nl of bij de auteurs van dit artikel op te vragen.
Dankbetuiging We danken de onderzoekers en interventieontwikkelaars die tijdens de ontwikkeling van het toetsingskader hun inzichten en feedback op een open en constructieve manier met ons gedeeld hebben.

Open Access This article is licensed under a Creative Commons Attribution 4.0 International License, which permits use, sharing, adaptation, distribution and reproduction in any medium or format, as long as you give appropriate credit to the original author(s) and the source, provide a link to the Creative Commons licence, and indicate if changes were made. The images or other third party material in this article are included in the article's Creative Commons licence, unless indicated otherwise in a credit line to the material. If material is not included in the article's Creative Commons licence and your intended use is not permitted by statutory regulation or exceeds the permitted use, you will need to obtain permission directly from the copyright holder. To view a copy of this licence, visit http://creativecommons.org/licenses/by/4.0/.

\section{Literatuur}

1. International Harm Reduction Association. What is harm reduction? A position statement from the international harm reduction association. London: IHRA; 2010.

2. Bartholomew LK, Parcel GS, Kok G. Intervention mapping: aprocessfor developing theory- and evidence-based health education programs. Health Educ Behav. 1998;25:545-63.

3. Lorenc T, Oliver K. Adverse effects of public health interventions: a conceptual framework. J Epidemiol Community Health. 2014;68:288-90.

4. Marlatt GA, Witkiewitz K. Harm reduction approaches to alcohol use: health promotion, prevention, and treatment. Addict Behav. 2002;27:867-86.

5. Ringold DJ. Boomerang effects in response to public health interventions: some unintended consequences in the alcoholic beverage market. J Consum Policy. 2002;25:27-63.

6. Cho H, Salmon CT. Unintended effects of health communication campaigns. J Commun. 2007;57:293-317.

7. Neighbors C, Lee CM, Lewis MA, Fossos N, Larimer ME. Are social norms the best predictor of outcomes among heavy drinking college students? J Stud Alcohol Drugs. 2007;68:556-65.

8. Hawkins JD, Catalano RF, Miller JY. Risk and protective factors for alcohol and other drug problems in adolescence and early adulthood: implications for substance abuse prevention. Psychol Bull. 1992;112:64-105.

9. Brewer NT, Weinstein ND, Cuite CL, Herrington JE. Risk perceptions and their relation to risk behavior. Ann Behav Med. 2004;27:125-30.

10. Leung KS, Abdallah AB, Cottler LB. Modifiable risk factors of ecstasy use: risk perception, current dependence, perceived control, and depression. Addict Behav. 2010;35:201.

11. Drummond DC. Theories of drug craving, ancient and modern. Addiction. 2001;96:33-46.

12. Abraham C, Michie S. A taxonomy of behavior change techniques used in interventions. Health Psychol. 2008;27:379-87. 